\title{
Hubungan Riwayat Komplikasi Saat Hamil dengan Kejadian Berat Badan Lahir Rendah (BBLR) di Indonesia
}

\section{Relationship History of Complications during Pregnancy with Low Birth Weight (LBW) in Indonesia}

\author{
Pebrina Manurung ${ }^{\mathrm{a}^{*}}$, Helda ${ }^{\mathrm{b}}$ \\ ${ }^{a}{ }^{*}$ Magister Prodi Epidemiologi Fakultas Kesehatan Masyarakat Universitas Indonesia, Lantai 1 Gedung A, Kampus UI Depok, Indonesia \\ ${ }^{\mathrm{b}}$ Departemen Epidemiologi, Fakultas Kesehatan Masyarakat Universitas Indonesia, Lantai 1 Gedung A, Kampus UI Depok, Indonesia
}

A B S T R A K

Bayi dengan Berat Badan Lahir Rendah (BBLR) berisiko mengalami banyak masalah kesehatan seperti jatuh sakit dalam enam hari pertama kehidupannya atau mengalami infeksi, serta dapat juga menderita masalah jangka panjang seperti perkembangan motorik dan sosial yang tertunda atau ketidakmampuan belajar. WHO memperkirakan BBLR sekitar $15 \%$ hingga $20 \%$ dari jumlah yang lahir, mewakili tiap tahunnya ada sekitar 20 juta kelahiran. Penelitian ini bertujuan untuk mengetahui hubungan riwayat komplikasi saat hamil dengan kejadian BBLR. Desain yang digunakan dalam penelitian ini yaitu study cross sectional dengan menganalisis data IFLS tahun 2014. Sebanyak 372 responden diikutkan dalam studi ini. Analisis chi square test untuk mengetahui hubungan antara exsposure (riwayat komplikasi saat hamil) dan outcome (BBLR) serta variabel lain yang diikutkan dalam penelitian ini yaitu jenis kelamin, urutan kelahiran dan konsumsi tablet Fe saat hamil sedangkan untuk analisis multivariat menggunakan regresi logistik ganda. Ada hubungan antara riwayat komplikasi saat hamil dengan kejadian BBLR dengan nilai asosiasi PR 2,123 (95\% CI 0,999-4,529), artinya ibu yang memiliki riwayat komplikasi saat hamil lebih beresiko 2,123 kali dibandingkan dengan ibu yang tidak memiliki riwayat komplikasi saat hamil untuk melahirkan anak BBLR. Riwayat komplikasi saat hamil berhubungan dengan terjadinya BBLR. Ibu hamil diharapkan dapat mencegah terjadinya komplikasi kehamilan dengan selalu memeriksakan kehamilannya ke tenaga kesehatan untuk dapat mendeteksi dini adanya komplikasi serta menanganinya agar tidak berdampak pada janin, dan ibu hamil juga sebaiknya patuh minum tablet Fe sesuai anjuran agar dapat mencegah terjadinya komplikasi anemia.

Kata kunci: Berat badan lahir rendah, komplikasi, kehamilan
A B S T R A C T

Infants with low birth weight are at risk of many health problems such as falling ill within the first six days of life or developing an infection, and can also suffer from long-term problems such as delayed motor and social development or learning disabilities. WHO estimates that LBW was around $15 \%$ to $20 \%$ of the number of births, representing about 20 million births each year. This study aims to determine the relationship between a history of complications during pregnancy with the incidence of LBW. The design used in this study was a cross-sectional study by analyzing the IFLS data 2014. A total of 372 respondents were included in this study. Chi square test analysis to determine the relationship between exposure (history of complications during pregnancy) and outcome (LBW) and other variables included in this study was gender, birth order and consumption of Fe tablets during pregnancy, while multivariate analysis used multiple logistic regression. There was an association between a history of complications during pregnancy with the incidence of LBW with a PR association value of 2.123 (95\% CI 0.999-4.529), the meaning that women who had a history of complications during pregnancy were 2,123 times more likely than mothers who do not have a history of complications during pregnancy to give birth to LBW children. Pregnant women are expected to prevent pregnancy complications by always checking their pregnancies with health personnel to detect complications early and treat them so that they do not affect the fetus, and pregnant women should also be obedient to taking Fe tablets as recommended in order to prevent complications from anemia.

Key words: Low birth weight, complications, pregnancy

\section{Pendahuluan}

WHO mendefinisikan bahwa bayi yang lahir dengan berat badan kurang dari 2500 gram disebut sebagai berat badan lahir rendah (BBLR). ${ }^{1}$ Menurut $\mathrm{CDC}$, berat badan lahir rendah dapat terjadi karena bayi yang lahir terlalu kecil dan dapat juga karena terlalu dini, atau dikarenakan keduanya. ${ }^{2}$ Bayi yang lahir terlalu dini (kelahiran prematur) artinya bayi tersebut lahir sebelum 37 minggu kehamilan sehingga bayi memiliki lebih sedikit waktu di rahim ibunya untuk tumbuh dan menambah berat badan. Sedangkan bayi lahir terlalu kecil merupakan suatu kondisi yang disebut pembatasan pertumbuhan intrauterine (IUGR). Hal ini terjadi ketika bayi tidak tumbuh dengan baik

*Korespondensi: Pebrina Manurung, Magiter Prodi Epidemiologi Fakultas Kesehatan Masyarakat Universitas Indonesia, Lantai 1 Gedung A, Kampus UI Depok, Indonesia Email: rina.manurung25@yahoo.co.id 
selama kehamilan yang dapat disebabkan karena masalah dengan plasenta, kesehatan ibu, atau kesehatan bayi. ${ }^{3}$ Dibandingkan dengan bayi dengan berat badan normal, bayi dengan berat badan lahir rendah lebih berisiko mengalami banyak masalah kesehatan seperti jatuh sakit dalam enam hari pertama kehidupannya atau mengalami infeksi, serta dapat juga menderita masalah jangka panjang seperti perkembangan motorik dan sosial yang tertunda atau ketidakmampuan belajar. ${ }^{2}$ WHO memperkirakan bahwa secara global dari 20 juta kelahiran terdapat sekitar $15 \%$ hingga $20 \%$ bayi yang lahir dengan berat badan lahir rendah tiap tahunnya. ${ }^{1}$

BBLR termasuk faktor utama penyebab tingginya angka morbiditas, mortalitas dan disabilitas, neonatus. ${ }^{4}$ Menurut WHO, pada 2017 terdapat 4,1 juta kematian bayi di dunia yang tejadi dalam tahun pertama kehidupan. ${ }^{5}$ Pada tahun 2015, Indonesia merupakan negara di ASEAN yang memiliki angka kematian bayi (AKB) tertinggi yaitu terdapat 22,23 kasus dari 1000 kelahiran hidup. ${ }^{6}$ Sedangkan prevalensi BBLR di Indonesia berdasarkan data Riskesdas pada tahun 2013 sebesar $10,2 \%$ dan sedikit meningkat menjadi $11,1 \%$ pada tahun 2010 selanjutnya tercatat menurun menjadi $6,2 \%$ pada tahun $2018 .^{7}$

Terdapat beberapa faktor yang berhubungan dengan BBLR yaitu pendidikan ibu, status sosial ekonomi, jarak kelahiran, jenis kelamin bayi, tenaga pemeriksaan kehamilan dan kualitas pelayanan antenatal. ${ }^{8}$ Faktor lain yang menjadi penyebab terjadinya anak BBLR yaitu faktor yang berasal dari ibu, plasenta, janin, dan yang berasal dari lingkungan disekitar. Berikut faktor-faktor yang berasal dari ibu yaitu usia saat hamil, pekerjaan, pendidikan, umur kehamilan, jarak kehamilan, paritas, kehamilan ganda, hipertensi, anemia, dan perilaku ibu. ${ }^{9}$ Menurut Sunarseh et al (2018), faktor-faktor yang berhubungan dengan BBLR yaitu jumlah paritas, pendidikan terakhir ibu, status ekonomi keluarga dan riwayat kesehatan ibu saat hamil. ${ }^{10}$

Berdasarkan hasil penelitian yang dilakukan oleh beberapa studi sebelumnya didapatkan hasil bahwa antara komplikasi kehamilan dengan BBLR terdapat hubungan yang signifikan atau bermakna secara statistik..$^{11,12}$ Menurut Nasution et al, ibu yang ada komplikasi kehamilan beresiko 3,7 kali dibandingkan dengan ibu yang tidak memiliki komplikasi saat hamil untuk melahirkan anak dengan BBLR (OR=3,675; 95\% CI 1,764-3,001). ${ }^{12}$

Pada penelitian ini, peneliti tidak hanya ingin melihat hubungan antara riwayat komplikasi saat hamil dengan kejadian BBLR, tetapi juga peneliti ingin menganalisis pengaruh variabel kovariat terhadap ada/ tidaknya hubungan antara riwayat komplikasi saat hamil dengan kejadian BBLR pada tahap analisis multivariat sehingga penulis mendapatkan hasil analisis yang murni hubungan riwayat komplikasi saat hamil dengan kejadian BBLR. Inilah yang menyebabkan penelitian ini berbeda dengan penelitian lain yang hanya melihat ada/tidaknya hubungan antara riwayat komplikasi saat hamil dengan kejadian BBLR tanpa mengontrol variabel kovariat atau penelitian yang bersifat prediktif yang pada tahap analisis multivariat hanya melihat variabel dominan saja. ${ }^{11,12,13}$ Oleh karena itu, berdasarkan uraian di atas penulis menganggap perlu dilakukan penelitian untuk mengetahui hubungan riwayat komplikasi saat hamil dengan kejadian BBLR berdasarkan data IFLS 2014. Penelitian ini diharapkan dapat menambah wawasan mengenai hubungan murni riwayat komplikasi saat hamil dengan kejadian BBLR setelah telah dikontrol oleh variabel lain serta dapat mengetahui langkah-langkah antisipasi terhadap komplikasi saat hamil dan penanganan pasca komplikasi agar dapat menurunkan prevalensi kejadian BBLR.

\section{Metode}

Pada penelitian ini, desain penelitian yang digunakan adalah penelitian observasional analitik dengan desain studi cross-sectional yaitu dimana faktor paparan (eksposure) dan kejadian penyakit/ kondisi kesehatan (outcome) diteliti dalam satu waktu. Penelitian menggunakan data sekunder yaitu data Indonesian Family Life Survey (IFLS) ke-5 yang dilakukan di 13 Provinsi di Indonesia pada tahun 2014. Penelitian ini dilakukan terhadap populasi wanita yang sudah pernah kawin usia 15 tahun sampai maksimal usia 57 tahun pada tahun 2014. Kriteria inklusi dalam penelitian ini yaitu ibu yang memiliki anak dan memiliki catatan kehamilan lengkap. Dari perhitungan sampel minimal dengan nilai prevalensi anak yang mengalami BBLR pada kelompok beresiko sama dengan $0,3^{14}$ dan prevalensi anak yang mengalami BBLR pada kelompok tidak beresiko adalah $0,25^{15}$, maka di dapat nilai sampel minimal sebesar 372 .

Pada studi ini analisis yang digunakan untuk mengetahui hubungan antara riwayat komplikasi saat hamil dengan BBLR yaitu chi square test dengan alpha 0,05 . Anak dinilai terlahir BBLR jika berat badan anak dari responden kurang dari $2.500 \mathrm{~g}$ dan dikatakan tidak BBLR atau normal jika berat badan anak responden $\geq 2.500$ g, data selanjutnya dikelompokkan menjadi dua ketagori yaitu BBLR dan normal. Responden dinilai memiliki riwayat komplikasi jika responden mengalami salah satu atau lebih komplikasi pada masa kehamilan dan dikatakan tidak memiliki riwayat 
komplikasi jika responden menjawab "tidak ada komplikasi" pada masa kehamilan. Peneliti melakukan analisis multivariat dengan menggunakan analisis regresi logistik ganda. Analisis multivariat digunakan untuk melihat adanya pengaruh variabel luaran (kovariat) terhadap hubungan riwayat komplikasi saat hamil dengan kejadian BBLR. Variabel kovariat yang diikutkan dalam analisis multivariat adalah variabel yang memiliki nilai $\mathrm{p}<0,25$ pada tahap analisis bivariat

Selanjutnya menilai variabel confounding dengan cara mengeluarkan variabel kovariat satu persatu dimulai dari variabel yang memiliki nilai $\mathrm{p}$ terbesar. Penilai terhadap variabel confounding berdasarkan perubahan nilai PR crude terhadap PR adjust. Perbedaan PR yang dilihat pada variabel utama, jika perbedaan $\mathrm{PR}>10 \%$ maka variabel tersebut adalah confounding dan tetap dipertahankan di dalam model. Namun jika perbedaan PR $<10 \%$ maka variabel tersebut bukan confounding dan harus dikeluarkan dari model hingga model akhir. Namun apabila secara substansial, variabel tersebut dianggap penting maka dapat tetap dimasukkan ke dalam model akhir walaupun perbedaan antara PR crude terhadap PR adjust $>10 \%$. Variabel kovariat yang diikutkan dalam studi ini yaitu jenis kelamin, konsumsi tablet besi selama kehamilan, dan urutan kelahiran anak. Ibu yang melahirkan lebih dari 3 kali atau jumlah paritas yang tinggi mempunyai risiko mengalami masalah kesehatan baik ibu maupun bayi yang dilahirkan seperti gangguan pada waktu kehamilan, persalinan dan nifas, bahkan kematian neonatal, sehingga peneliti menggunakan batas pengkategorian beresiko jika urutan kelahiran anak $\geq 4$ dan tidak beresiko $<4$. . $^{16,17}$

\section{Hasil}

Tabel 1. Karakteristik Demografik

\begin{tabular}{lcc}
\hline \multicolumn{1}{c}{ Variabel } & n & \% \\
\hline Variabel Dependen & & \\
Status BBLR & & \\
BBLR & 39 & 10,5 \\
Normal & 333 & 89,5 \\
Variabel Independen & & \\
Riwayat Komplikasi Saat Hamil & & \\
Komplikasi & 63 & 16,9 \\
Tidak Komplikasi & 309 & 83,1 \\
Variabel Kovariat & & \\
Jenis Kelamin Anak & & \\
Laki-laki & 170 & 45,7 \\
Perempuan & 202 & 54,3 \\
Urutan Kelahiran & & \\
>=4 & 31 & 8,3 \\
< 4 & 341 & 91,7 \\
Konsumsi Tablet Fe Saat Hamil & & \\
Ya & 49 & 13,2 \\
Tidak & 323 & 86,8 \\
\hline
\end{tabular}

Berdasarkan hasil analisis univariat pada tabel 1, dari 372 responden didapat $10,5 \%$ ibu yang melahirkan bayi dengan BBLR dan $89,5 \%$ ibu yang melahirkan bayi normal (tidak BBLR). Pada variabel riwayat komplikasi ibu saat hamil didapat $16,9 \%$ ibu yang mengalami komplikasi dan 83,1\% ibu yang tidak mengalami komplikasi. Untuk proporsi jenis kelamin anak, didapat sebanyak 45,7\% laki-laki sedangkan sebanyak 54,3\% perempuan. Berdasarkan variabel urutan kelahiran, didapat 8,3\% anak yang berada pada urutan kelahiran $\geq 4$ dan $91,7 \%$ anak yang berada pada urutan kelahiran $<4$.

Tabel 2. Hubungan antara Variabel Studi dengan BBLR

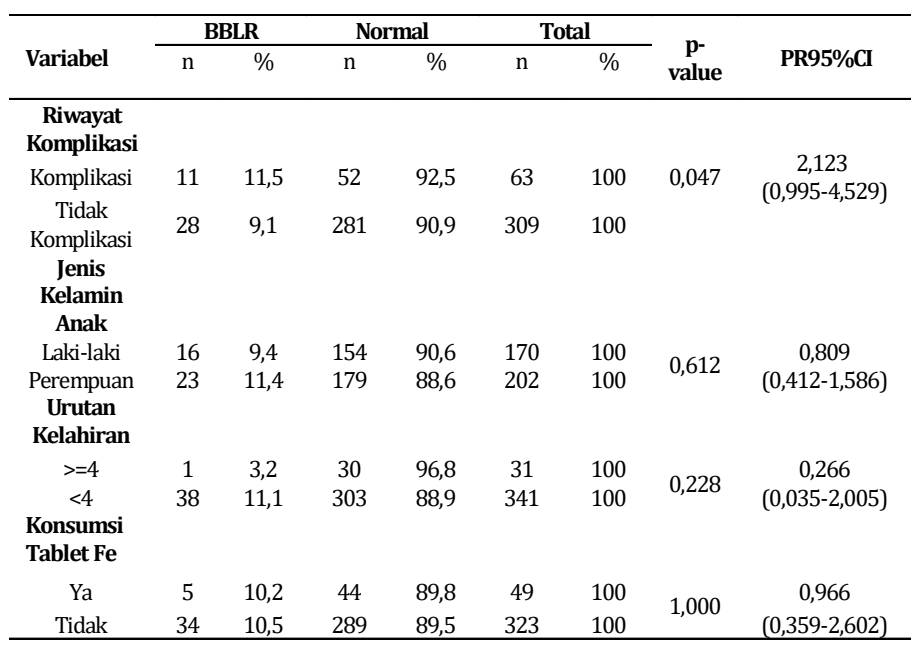

Pada tabel 2 di atas, hasil analisis bivariat dapat kita dilihat bahwa ibu yang memiliki riwayat komplikasi saat hamil beresiko 2,123 kali untuk melahirkan anak degan BBLR lebih tinggi dibandingkan ibu yang tidak memiliki riwayat komplikasi saat hamil

(95\% CI 0,999-4,529).

Tabel 3. Model Akhir Multivariat

\begin{tabular}{lcccc}
\hline \multirow{2}{*}{ Variabel } & \multirow{2}{*}{ PR } & \multicolumn{2}{c}{$95 \%$ CI } & \multirow{2}{*}{ p-value } \\
\cline { 3 - 4 } & & Lower & Upper & \\
\hline Riwayat komplikasi & 2,000 & 0,934 & 4,283 & 0,075 \\
Urutan kelahiran & 0,301 & 0,040 & 2,287 & 0,246 \\
Konsumsi tablet Fe & 0,930 & 0,342 & 2,527 & 0,887 \\
\hline
\end{tabular}

Pada tabel 3 dapat kita lihat model akhir dari analisis multivariat, bahwa ibu yang memiliki riwayat komplikasi saat hamil beresiko 2 kali untuk melahirkan anak degan BBLR lebih tinggi dibandingkan ibu yang tidak memiliki riwayat komplikasi saat hamil setelah dikontrol oleh variabel urutan kelahiran dan konsumsi tablet Fe (nilai $p=0,075 ; 95 \%$ CI 0,934-4,283). 


\section{Pembahasan}

Prvalensi BBLR pada penelitian ini yaitu dari 372 responden didapat 39 responden yang melahirkan anak dengan BBLR sedangkan 333 responden yang melahirkan anak dengan berat badan normal. Hasil analisis bivariat dalam penelitian ini yaitu terdapat hubungan antara riwayat komplikasi saat hamil dengan kejadian BBBL dengan $p$-value $=0,047(<0,05)$ yang artinya bermakna signifikan secara statistik. Besar asosiasi atau nilai PR yang didapat adalah 2,123 (95\% CI 0,999-4,529), artinya ibu yang memiliki riwayat komplikasi saat hamil berisiko 2,123 kali lebih besar dibandingkan dengan ibu yang tidak memiliki riwayat komplikasi saat hamil untuk melahirkan anak dengan BBLR.

Penelitian yang dilakukan oleh Indrasari (2012) hasilnya sama dengan penelitian ini yaitu pada analisis statistik didapat nilai $p=0,009(<0,05)$ yang bermakna signifikan dan nilai asosiasi 2,5 yang artinya ibu yang ada riwayat komplikasi saat hamil memiliki risiko 2,5 kali melahirkan anak dengan BBLR dibandingkan ibu yang tidak ada riwayat komplikasi saat hamil. Ibu yang memiliki riwayat komplikasi saat hamil akan mempengaruhi pertumbuhan janin dalam kandungan sehingga memiliki risiko untuk melahirkan bayi BBLR. Indrasari menyatakan BBLR dapat terjadi pada ibu yang mengalami gangguan/komplikasi selama kehamilan seperti hipertensi, hipotensi, anemia, preeklampsia dan eklamsia karena dapat memperpendek usia kehamilan dan janin tumbuh lambat. ${ }^{18}$ Nasution et al (2018) pada penelitiannya menyatakan bahwa hasil analisis statistiknya didapat p-value $=<0,001$ yang bermakna signifikan dengan hasil mayoritas ibu pada kelompok kasus didapat memiliki anak dengan BBLR dan nilai OR yang didapat $=3,675$ dengan rentang 95\% CI 1,764-3,001. Nasution juga menyatakan komplikasi kehamilan yang sangat mengancam janin dan kesehatan ibu serta mendesak kelahiran segera, dapat mengakibatkan BBLR. ${ }^{12}$ Penelitian lain yaitu Simarmata et al (2010) juga menyatakan bahwa berdasarkan hasil analisis statistik didapat hubungan komplikasi kehamilan dengan kejadian BBLR yang bermakna signifikan yaitu p-value $=0,003$ dan $\mathrm{OR}=1,53$ rentang $95 \%$ CI 1,16-2,02. ${ }^{19}$ Mulyanti dan Ekaningrum menyatakan, semakin banyak ibu mengalami komplikasi kehamilan maka akan semakin tinggi risiko kelahiran bayi dengan BBLR karena kesehatan ibu akan semakin melemah sehingga pertumbuhan jani terhambat dan mengakibatkan BBLR. ${ }^{8,11}$ Komplikasi saat hamil merupakan masalah kesehatan yang sering terjadi saat masa kehamilan maupun juga saat persalinan. Konsekuensi dari terjadinya komplikasi saat hamil yaitu dapat menyebabkan masalah kesehatan pada ibu, bayi ketika dilahirkan, ataupun kesehatan keduanya. ${ }^{20}$

Meskipun hasil penelitian ini memiliki hasil yang sama dengan Indrasari (2012) namun analisis multivariat yang dilakukan Indrasari bersifat prediktif, tidak dapat menampilkan hasil murni dengan mengontrol variabel lain yang mungkin dapat berpengaruh terhadap hubungan riwayat komplikasi dengan kejadian BBLR, desain yang digunakan juga berbeda yaitu case control. ${ }^{18}$ Analisi yang dilakukan oleh Mulyanti (2015) juga menyatakan hasil analisis yang sama dengan penelitian ini, namun peneliti Mulyanti (2015) tidak melakukan analisis multivariat hanya melihat hubungan antara komplikasi kehamilan dengan BBLR. ${ }^{11}$ Begitu pula dengan penelitian yang dilakukan oleh Ekaningrum et al (2014) di Indonesia dengan menggunakan data SDKI 2012, hasil analisis multivariat untuk model akhir diperoleh hubungan antara komplikasi kehamilan dengan BBLR setelah dikontrol oleh beberapa variabel didapat hasil yang signifikan secara statistik dengan OR 1,78 (95\% CI 1,45$2,19) .{ }^{8}$ Berbeda dengan penelitian ini, hasil multivariat yang diperoleh setelah dikontrol oleh variabel kovariat, tidak signifikan secara statistik meskipun nilai PR yang diperoleh 2 (95\% CI 0,934-4,283), serta sampel yang diteliti sedikit yaitu 372 responden dibandingkan penelitian Ekaningrum et al (2014) dengan sampel 13.143 responden.

Pada hasil analisis multivariat, variabel kovariat yang dikontrol terhadap hubungan riwayat komplikasi saat hamil dengan kejadian BBLR adalah urutan kelahiran dan konsumsi tablet Fe. Menurut Pinontoan et al (2015), masalah kesehatan yang terjadi pada ibu maupun bayi yang dilahirkan dapat diakibatkan oleh jumlah paritas (kelahiran) yang tinggi. ${ }^{21}$ Ibu akan memiliki risiko mengalami komplikasi serius seperti perdarahan jika jumlah paritas lebih dari 3 kali. Pendarahan yang terjadi ini dapat dipengaruhi oleh keadaan anemia selama kehamilan. Ibu dapat kehilangan banyak haemoglobin dan ibu akan mengalami penurunan cadangan zat besi, yang mengakibatkan pada kehamilan selanjutnya ibu akan memiliki risiko lebih besar untuk mengalami anemia lagi, hal ini diakibatkan oleh pendarahan yang terjadi. ${ }^{22}$ Mengonsumsi suplemen zat besi pada ibu secara rutin merupakan salah satu cara memperbaiki masalah global kekurangan zat besi dan juga dapat mencegah dampak negatifnya. ${ }^{23}$ Susiloningtyas (2012) mengungkapkan bahwa kurangnya zat besi pada ibu mengakibatkan masalah anemia pada ibu saat hamil karena adanya peningkatan kebutuhan zat besi yang lebih pada ibu saat hamil. ${ }^{23}$ Menurut Manuaba (2012) ibu yang mengalami anemia dapat berdampak pada kelahiran bayi yaitu premature, BBLR, morbiditas dan 
mortalitas. ${ }^{24}$ Sangat ideal untuk memulai mengonsumsi suplemen zat besi sebelum konsepsi atau sesegera mungkin untuk mengurangi risiko prematuritas dan BBLR. $^{24}$

\section{Kesimpulan}

Peneliti menyimpulkan berdasarkan hasil analisis yaitu bahwa riwayat komplikasi saat hamil berhubungan terhadap kejadian BBLR. Oleh karena itu, peneliti mengusulkan kepada ibu hamil agar rajin memeriksakan kehamilan kepada bidan atau dokter untuk dapat mendeteksi dini bahkan mencegah terjadinya komplikasi kehamilan sehingga tidak mempengaruhi pertumbuhan janin dalam kandungan dan ibu hamil diharapkan patuh minum tablet Fe sesuai dengan anjuran bidan atau dokter, agar dapat mengurangi terjadinya komplikasi berupa enemia yang dapat memberikan dampak pada kelahiran bayi serta sebaiknya ibu merencanakan kehamilan dengan konseling ke tenaga kesehatan terkait dengan jumlah paritas atau kelahiran yang dapat membahayakan kandungan nantinya agar dapat mengurangi risiko kelahiran BBLR. Peneliti juga mengusulkan kepada peneliti lebih lanjut, untuk mengembangkan metode penelitian yang lebih dalam serta menganalisis faktor risiko lain yang tidak ada pada penelitian ini yang berhubungan dengan kejadian BBLR.

\section{Daftar Pustaka}

1. World Health Organization (WHO) [Internet]. Global Nutrition Targets 2025: Low birth weight policy brief; 2020 [cited 2020 July 28].

2. Centers for Disease Control and Prevention [Internet]. Reproductive and Birth Outcomes [cited 2020 Sept 08].

3. Stanford Children's Health [Internet]. Low Birth Weight. [cited 2020 Sept 08].

4. Nelwan JE. Epidemiologi Kesehatan Reproduksi. Sleman : CV Budi Utama;2019

5. World Health Organization (WHO) [Internet]. Infant Mortality [cited 2020 Sept 9].

6. Cha S. The impact of the worldwide Millennium Development Goals campaign on maternal and underfive child mortality reduction: 'Where did the worldwide campaign work most effectively?'. Glob Health Action. 2017;10(1):1267961.

7. Riskesdas. Hasil utama Riset Kesehatan Dasar (RISKESDAS) [Internet]. 2018.

8. Ekaningrum AY, Ariawan I, Prasetyo SB, Raharja MB. Hubungan komplikasi kehamilan dengan kejadian bayi berat lahir rendah di Indonesia tahun 2012 : analisis SDKI 2012 [skripsi]. Depok : Kesehatan Masyarakat Universitas Indonesia; 2014

8. Ekaningrum AY, Ariawan I, Prasetyo SB, Raharja MB. Hubungan komplikasi kehamilan dengan kejadian bayi berat lahir rendah di Indonesia tahun 2012 : analisis SDKI 2012 [skripsi]. Depok : FKM Universitas Indonesia; 2014

9. Pantiawati. Bayi dengan BBLR. Yogyakarta : Nuha Medika; 2010

10. Sunarseh, Wahtini S. Faktor-faktor yang berhubungan dengan kejadian BBLR di UPT Puskesmas Rawat Jalan Saptosar Gunungkidul [Internet]. 2018

11. Mulyanti. Hubungan antara komplikasi kehamilan dengan kejadian BBLR di Rumah Sakit Umum Daerah Kelas B Kabupaten Subang [Internet]. J Kesehatan. Vol 1, No.1, Th, 2015:145-150.

12. Nasution SM, Sanusi SR, Aritonang EY. Pengaruh usia kehamilan, jarak kehamilan, komplikasi kehamilan, antenatal care terhadap kejadian bayi berat lahir rendah (BBLR) di RSUD dr. Pirngadi Kota Medan Tahun 2017 [tesis]. Medan: Program Studi S2 Kesehatan Masyarakat Universitas Sumatera Utara; 2018.

13. Kusumawati DD, Septiyaningsih R, Kania. Faktor-faktor ibu yang mempengaruhi kejadian bayi berat lahir rendah (BBLR). Jurnal Kesehatan Al-Irsyad (JKA), Vol. IX, No. 2; 2016

14. Kelsey JL, Whittemore AS, Evans AS, Thompson WD. Methods in observational epidemiology. 2nd ed. Madison Avenue, New York: Oxferd Universsity Press, Inc; 1996.

15. Ila SLL, Avianty I, Nasution A. Faktor-faktor yang berhubungan dengan risiko kejadian bayi berat lahir rendah (BBLR) di Puskesmas Tegal Gundil Kota Bogor tahun 2018. Jurnal Mahasiswa Kesehatan Masyarakat, Vol. 2 No.3 ;2019

16. Rohmatin H, Widayanti A, Narsih U. Mencegah Kematian Neonatal dengan P4K. Jakarta: Universi Wisnuwardana Press (Unidha Press) ; 2018

17. Lubis NM. Pskologi Kespro "Wanita \& Perkembangan Reproduksi" ditinjau dari Aspek Fisik dan Psikologi. Jakarta : PT Fajar Interpratama Mandiri; 2013

18. Indrasari N. Faktor resiko pada kejadian berat badan lahir rendah (BBLR) [Internet]. Jurnal Keperawatan, Volume VIII, No. 2, Oktober 2012.

19. Simarmata OS, Siregar KN. Hubungan kualitas pelayanan antenatal terhadap kejadian BBLR di Indonesia [tesis]. Depok: Program Studi Ilmu Kesehatan Masyarakat Kekhususan Kesehatan Reproduksi Universitas Indonesia; 2010.

20. Prawirohardjo, S. Ilmu kebidanan sarwoni prawirihardjo. Jakarta: PT. Bina Pustaka Sarwono Prawirohardjo; 2014

21. Pinontoan VM, Tombokan SGJ. Hubungan umur dan paritas dengan kejadian bayi berat lahir rendah. J Ilmiah Bidan [Internet]. 2015

22. Kusumah UW, Talla ZZ, Barus RP. Kadar hemoglobin ibu hamil trimester II-III dan faktor-faktor yang mempengaruhinya di RSUP H. Adam Malik Medan Tahun 2009 [tesis]. Medan : Program Magister Kedokteran Klinik Universitas Sumatera Utara; 2009.

23. Abu-Ouf N M, Jan MM. The impact of maternal iron deficiency and iron deficiency anemia on child's health. Saudi Med J. 2015; 36(2): 146-149.

24. Susiloningtyas I. Pemberian zat besi (Fe) dalam kehamilan. Majalah Ilmiah Sultan Agung. Vol 50, No 128 (2012) ; 2012. 25 Manuaba IBG. Ilmu kebidanan penyakit kandungan dan Keluarga Berencana untuk Pendidikan Bidan. Jakarta. EGC; 2012. 
Jurnal Epidemiologi Kesehatan Indonesia Vol 4. No. 2, Desember 2020 